\title{
An Investigation into the Association Between Toxoplasma gondii Infection and Bipolar Disorder
}

\author{
Toxoplasma gondii Enfeksiyonu ile Bipolar Bozukluk Arasindaki İlişkiye \\ Yönelik Bir Araştırma
}

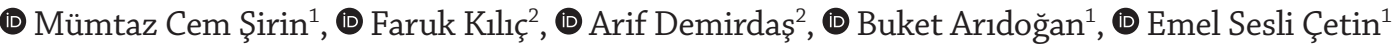 \\ ${ }^{1}$ Süleyman Demirel University Faculty of Medicine, Department of Medical Microbiology, Isparta, Turkey \\ ${ }^{2}$ Süleyman Demirel University Faculty of Medicine, Department of Psychiatry, Isparta, Turkey
}

Cite this article as: Şirin MC, Kılıç F, Demirdaş A, Arıdoğan B, Sesli Çetin E. An Investigation into the Association Between

Toxoplasma gondii Infection and Bipolar Disorder. Turkiye Parazitol Derg 2021;45(4):241-6.

\begin{abstract}
Objective: Studies have implicated Toxoplasma gondii in the etiology of mental disorders because of its neurotropic nature and its ability to modulate neurotransmitter pathways. This study aims to investigate $T$. gondii seroprevalence in patients with bipolar disorder and in healthy controls living in the Isparta Region of Turkey and to assess the probable relationship between $T$. gondii and bipolar disorder.

Methods: Fourty-eight patients with bipolar disorder and 50 healthy controls were included in the study. Sociodemographic data, possible risk factors for T. gondii infection and clinical characteristics were analyzed. Serum anti-T. gondii IgM and IgG antibody levels were measured by using chemiluminescence immunoassay method (Roche Cobas e601 analyzer, Roche Diagnostics, Mannheim, Germany).

Results: Anti-T. gondii IgG seropositivity rates were determined as $18.8 \%$ and $20 \%$ in the patient group and the control group, respectively. No statistically significant relationship was observed between $T$. gondii IgG seropositivity and bipolar disorder $(\mathrm{p}=0.876)$. In the study population, advanced age, low education level, living in a rural region and consumption of unwashed raw vegetable or fruit were found to be the significant risk factors for T. gondii infection $(\mathrm{p}<0.05)$.

Conclusion: Our preliminary findings do not support the hypothesis that $T$. gondii infection is related to bipolar disorder. However, further studies would require larger sample sizes to confirm our results.

Keywords: Toxoplasma gondii, bipolar disorder, seroprevalence
\end{abstract}

\section{öz}

Amaç: Toxoplasma gondii’nin nörotropik yapısı ve nörotransmitter yolaklarını modüle etme yeteneği nedeniyle ruhsal bozuklukların etiyolojisinde rol oynadığı öne sürülmüştür. Bu çalışmanın amacı, Türkiye'de Isparta Bölgesi'nde yaşayan bipolar bozukluğu olan hastalarda ve sağlıklı kontrollerde $T$. gondii seroprevalansını araştırmak ve $T$. gondii ile bipolar bozukluk arasındaki olası ilişkiyi değerlendirmektir.

Yöntemler: Çalışmaya bipolar bozukluğu olan 48 hasta ve 50 sağlıklı kontrol dahil edildi. Sosyo-demografik veriler, T. gondii enfeksiyonu için olası risk faktörleri ve klinik özellikler analiz edildi. Serum anti-T.gondii IgM ve IgG antikor seviyeleri kemilüminesans immunoassay yöntemi (Roche Cobas e601, Roche Diagnostics, Mannheim, Almanya) kullanılarak ölçüldü.

Bulgular: Anti-T.gondii IgG seropozitiflik oranları hasta grubunda ve kontrol grubunda sirasıyla \%18,8 ve \%20 olarak belirlendi. T. gondii IgG seropozitifliği ile bipolar bozukluk arasında istatistiksel olarak anlamlı bir ilişki gözlenmedi ( $\mathrm{p}=0,876)$. Çalışma popülasyonunda, ileri yaş, düşük eğitim düzeyi, kırsal bölgede yaşama ve yıkanmamış çiğ sebze veya meyve tüketimi $T$. gondii enfeksiyonu için anlamlı risk faktörleri olarak bulundu $(\mathrm{p}<0,05)$.

Sonuç: Bulgularımız, T. gondii enfeksiyonunun bipolar bozuklukla ilişkili olduğu hipotezini desteklememektedir. Sonuçlarımızın doğrulanması için daha büyük örneklemlere sahip çalışmalara ihtiyaç bulunmaktadır.

Anahtar Kelimeler: Toxoplasma gondii, bipolar bozukluk, seroprevalans 


\section{INTRODUCTION}

Bipolar disorder is a debilitating chronic psychiatric disease affecting approximately $1-2 \%$ of the general population (1). Its clinical course is usually characterized by recurrent episodes of depression and mania, interspersed with normal euthymic periods, and the illness imposes a significant burden on the affected individuals and their families with serious socioeconomic consequences $(2,3)$. There are two common types of bipolar disorder: Type I (at least one episode of full-blown mania or mixed episode) and type II (several protracted depressive episodes and at least one hypomanic episode, but no full-blown manic episodes) (2). The etiology and pathogenesis of this mood disorder is not yet fully understood. Besides genetic and multiple environmental factors, immunological abnormalities and neuroinflammation have been regarded as possible contributors to the pathophysiology of bipolar disorder $(4,5)$.

In recent years, the implication of infectious agents, especially Toxoplasma gondii, in the development of psychiatric disorders has gained increasing attention (5-7). Various infectious agents, bacteria, viruses or parasites, can cause neuropsychiatric symptoms both directly, by affecting neurons, glial cells and brain structures, and indirectly, by the stimulation of a microbe-specific immune response and the subsequent release of proinflammatory cytokines and neurotoxic factors $(5,8,9)$.

T. gondii, the causative agent of toxoplasmosis, is an obligate intracellular protozoan parasite and it is assumed that approximately $25-30 \%$ of the world population is infected with this pathogen (10). In the latent stage of the infection, parasite can persist within cysts forms in neurons, microglia and astrocytes and in muscle cells throughout the life of the host (10-12). Although latent toxoplasmosis, diagnosed by immunoglobulin (Ig) $G$ antibodies against T. gondii, was generally assumed to be asymptomatic in immunocompetent hosts, it is now proposed that it can induce cognitive and behavioral alterations in infected rodents and humans $(5,13)$. The exact mechanism by which latent toxoplasmosis modifies cognition and behaviour is unclear. However, studies in animal models suggest that personality and behavior changes in rodents may occur as a result of the local inflammatory response induced by $T$. gondii neural cysts $(4,13)$. Dormant parasites may also influence neurotransmitter pathways, and initiate a cascade of events leading to neuroinflammation and neurodegeneration by the direct stimulation of inflammatory cytokines in the central nervous system. T. gondii has been shown to increase dopamine concentration in the brain, as well as to modulate serotonin, glutamate and gamma-aminobutyric acid signaling, all of which are involved in the pathogenesis of psychological disturbances $(4,5,14)$.

Among psychiatric disorders, T. gondii has been studied most extensively in schizophrenia, and a substantial body of literature have reported significantly increased levels of T. gondii antibodies in the serum of individuals with schizophrenia (4,14-16). However, contrary to schizophrenia, the role of toxoplasmosis as a risk factor for bipolar disorder remains controversial. While some studies have demonstrated a positive correlation between $T$. gondii seropositivity and bipolar disorder, others have not supported the role of $T$. gondii infection as a putative risk factor for bipolar disorder $(4,5,7,14,17-27)$.

In Turkey, there is limited information about the epidemiology of $T$. gondii infection in psychiatric patients, and only one study was conducted examining the possible relationship between $T$. gondii and bipolar disorder (21). The aim of the present study was to investigate $T$. gondii prevalence in individuals with bipolar disorder and in healthy controls living in Isparta region of Turkey by using serologic diagnostic methods, and to evaluate the correlation between $T$. gondii and this mood disorder.

\section{METHODS}

This cross-sectional study was performed at the Department of Psychiatry in collaboration with the Department of Medical Microbiology, Süleyman Demirel University Research and Practice Hospital, between January 2019 and December 2019. Ethical approval was obtained from the Ethics Committee of Süleyman Demirel University Faculty of Medicine. The research was conducted in accordance with the Helsinki Declaration, and written informed consent was taken from all the participants.

\section{Patients and Controls}

Subjects with any autoimmune disease, malignancy, severe chronic disease, recent infectious disease, comorbid psychiatric disease, cognitive impairment or dementia were excluded from the study. In the patient group $(n=48)$, the diagnosis of bipolar disorder was established by an experienced psychiatrist according to the diagnostic and statistical manual of mental disorders, fourth edition, text revision criteria via independent clinical interview. The young mania rating scale (YMRS) and the Hamilton depression rating scale (HDRS) were used to evaluate the severity of manic and depressive symptoms, respectively. Euthymia was determined by YMRS score less than 7 and HDRS score less than 7 points. The control group $(n=50)$ consisted of healthy volunteers with no personal or family history of psychiatric disorder attending outpatient clinics for routine health checkup. Data concerning probable risk factors for T. gondii infection (current or past living in a rural region, contact with cats; having a cat at home or playing closely with cats, consumption of raw or undercooked meat, consumption of unwashed raw vegetable or fruit, contact with soil; gardening or agricultural activities), sociodemographic data (age, gender, education level, socio-economic status) and clinical characteristics (bipolar disorder type, current mood status, duration of illness, number of lifetime episodes, YMRS, HDRS, family predisposition, suicide attempt history, lifetime total duration of medication) were recorded after clinical interviews.

\section{Serological Analysis}

Venous blood samples were taken from each subject, and then centrifuged prior to analysis. The serum anti-T. gondii IgM and IgG levels were measured by using an automated chemiluminescence immunoassay method (Roche Cobas e601 analyzer, Roche Diagnostics, Mannheim, Germany). Anti-T. gondii IgM test result of $\geq 1.0 \mathrm{COI}$ and anti- $T$. gondii IgG test result of $\geq 3 \mathrm{IU} / \mathrm{mL}$ were considered as positive, according to the manufacturer's guidelines. All positive test results were retested in duplicate. The presence of anti-T. gondii IgM antibody suggested recent infection, while a positive test result for anti-T. gondii $\operatorname{IgG}$ antibody indicated past infection with T. gondii.

\section{Statistical Analysis}

Statistical analysis was performed using the Statistical Package for the Social Sciences (SPSS) version 22 (SPSS Inc., Chicago, IL, USA). 
The Kolmogorov-Smirnov test was used to assess the normality of the data. Accordingly, Student's t-test or Mann-Whitney U test was used to compare the differences in continuous variables between groups. The chi-square test with Bonferroni correction was used for categorical variables. Odds ratios (OR) and 95\% confidence intervals (CIs) were calculated. Results were expressed as frequencies and percentages, or mean \pm standard deviation. A p-value of $<0.05$ was considered statistically significant.

\section{RESULTS}

Fourty-eight patients with bipolar disorder (35 were type I and 13 were type II) and 50 healthy controls with similar age and sex distribution were included in the study. Comparison of sociodemographic data, possible risk factors for T. gondii infection, T. gondii seropositivity status and clinical characteristics in the patient and control groups is shown in Table 1.

None of the subjects was in an acute phase of T. gondii infection and revealed anti-T. gondii IgM seropositivity. Anti-T. gondii IgG positivity was found in 9 (18.8\%; CI: 10.2-31.9) of the 48 patients with bipolar disorder and in 10 (20\%; CI: 11.2-33) of the 50 control subjects (Table 1 ). No statistically significant association was observed between T. gondii IgG seropositivity and bipolar disorder (OR=0.923; CI: 0.339-2.516, $\mathrm{p}=0.876$ ). In terms of IgG titers (serointensity), the difference was not significant $(\mathrm{p}=0.619)$ between the seropositive patients $(293.84 \pm 180.23 \mathrm{IU} / \mathrm{mL})$ and the seropositive controls $(240.81 \pm 262.57 \mathrm{IU} / \mathrm{mL}$ ) (data not shown).

The patient group and the control group did not differ significantly for age, age subgroups, gender, education level, socio-economic status, residence in rural region, contact with cats, raw or undercooked meat consumption, unwashed raw vegetable or fruit consumption and contact with soil ( $\mathrm{p}>0.05$ ) (Table 1).

In the patient group, six (66.7\%) of the seropositive patients $(n=9)$ were diagnosed as type II bipolar disorder and 3 (33.3\%) of them as type I bipolar disorder (data not shown). The seropositive patients were found to be significantly $(\mathrm{p}=0.004)$ older than the seronegative patients (Table 2). Consumption of unwashed raw vegetable or fruit also differed significantly $(\mathrm{p}=0.001)$ between the seropositive patients and the seronegative patients (Table 2). In the study population ( $\mathrm{n}=98)$, there were significant differences in the age $(p=0.001)$, education level $(p=0.015)$, residence in rural region $(p=0.039)$ and unwashed raw vegetable or fruit consumption $(\mathrm{p}=0.001)$ between the seropositive participants $(\mathrm{n}=19)$ and the seronegative participants $(\mathrm{n}=79)$ (Table 2). Advanced age, low education level, living in a rural region and consumption of unwashed raw vegetable or fruit were determined as the significant risk factors for T. gondii infection in our study population.

\section{DISCUSSION}

Its neurotropic nature and the ability of affecting neurotransmitter pathways and immune system functions have made $T$. gondii an attractive candidate as a potential causative agent for psychiatric and neurodegenerative disorders $(6,15)$. In contrast to numerous publications dealing with the relationship between $T$. gondii and schizophrenia $(15,16)$, the link between this pathogen and bipolar disorder was relatively understudied. In addition, available data are still inconsistent (4). In this regard, we aimed to determine whether bipolar disorder is associated with $T$. gondii seropositivity in our study population in Isparta, Turkey.

It is well-known that the prevalence of $T$. gondii infection varies widely by age, ethnic group, nutritional habits, socio-economic status, and geographic region $(10,11)$. For instance, according to the seroprevalence studies in different countries, the IgG seropositivity rate was reported as $4 \%$ in South Korea, $9 \%$ in England, 11\% in China, 23\% in Italy, 35\% in New Zealand, 42\% in Egypt, 50\% in Brazil, 54\% in France, 60\% in Argentina, and $76 \%$ in Costa Rica (28). In our country, the seroprevalence of toxoplasmosis varies among different regions and populations, ranging from $17.5 \%$ to $69.5 \%(29,30)$. In the present study, we found anti-T. gondii IgG positivity rates as $18.8 \%$ and $20 \%$ in the patient group and control group, respectively. The seropositivity rates in both groups were similar to the findings reported in T. gondii seroprevalence studies in our country. However, the difference between the groups was not statistically significant ( $p>0.05$ ) in terms of association between T. gondii infection and bipolar disorder.

In contrast to our findings, some researchers have found significantly elevated $T$. gondii seroprevalence in patients with bipolar disorder (7,14,18-20). An Ethiopian case-control study (18) revealed a significantly higher seropositivity rate for $T$. gondii infection (OR:3) in bipolar patients (95.3\%) compared to unaffected controls (87.3\%). In another case-control seroprevalence study from France, the prevalence of $T$. gondii infection was compared in a sample of 110 patients with bipolar disorder and 106 healthy controls (7). The results of this study showed that the seropositive group for IgG antibodies had a 3.6 fold increased odds of having the disease as compared to the seronegative group. In a population-based cross-sectional survey conducted in the United States, Pearce et al. (14) reported that T. gondii seroprevalence was not elevated in unipolar mood disorders ( $p>0.05$ ), but a significant association was found between $T$. gondii seroprevalence and bipolar disorder type I $(\mathrm{OR}=2.4, \mathrm{p}<0.05)$.

Due to the neurotropic properties of $T$. gondii as noted above, the hypothesis that $T$. gondii may be a possible cause of bipolar disorder seems quite reasonable. However, there are some difficulties with this proposition as also indicated in previous publications $(6,15)$, and debate still exists on this causal relationship. The main issue is the obvious epidemiological inconsistency. Countries with a high seroprevalence of toxoplasmosis do not have a corresponding increased bipolar disorder prevalence and unlike toxoplasmosis, bipolar disease does not exhibit such marked geographic variation in prevalence $(1,6)$. Hence, if T. gondii causes bipolar disorder as suggested, it can only lead to bipolar disorder in a fraction of individuals it infects. Secondly, in previous studies, it has not been feasible to demonstrate a relation between toxoplasmosis and the timing of onset of this psychiatric disease. Bipolar disorder is a complex condition that results from multiple interacting factors and it can be very difficult to show solely this relation. Lastly, if the relation between toxoplasmosis and bipolar disorder is confirmed, specific anti-protozoal therapy may prevent the development of bipolar disorder. However, there is not yet strong evidence from treatment trials that precisely evaluated the efficacy of antiprotozoal therapy against toxoplasmosis in patients suffering from bipolar disorder $(6,7)$.

Furthermore, it should be noted that there have been some studies which have failed to find a statistically significant association between exposure to T. gondii and risk of bipolar disorder (21- 
Table 1. Comparison of socio-demographic data, possible risk factors for T. gondii infection, T. gondii seropositivity status and clinical characteristics in the patient and control groups

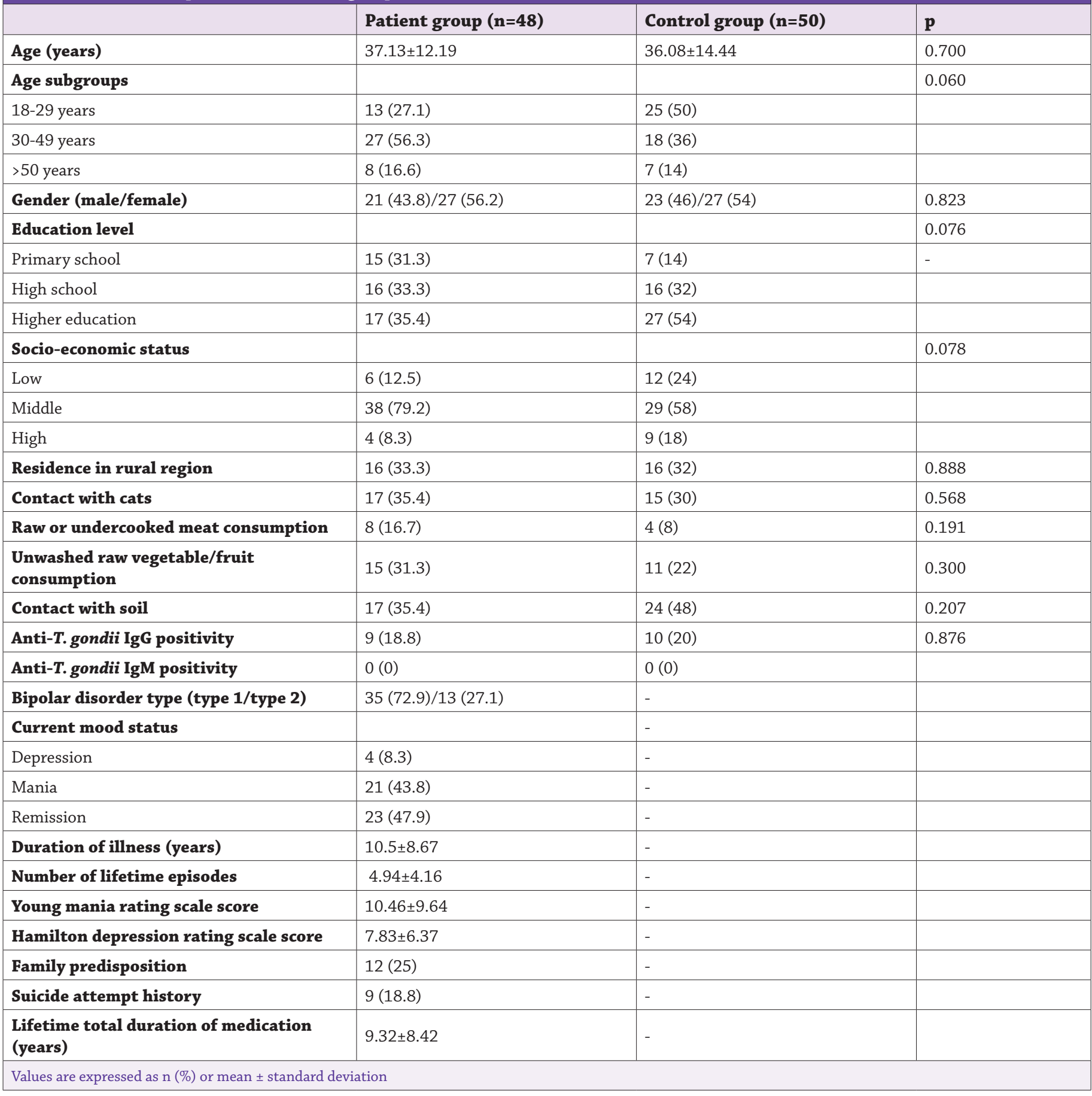

27). To our knowledge, only one study in our country investigated the possible relationship between T. gondii infection and bipolar disorder, and no significant relationship was detected in this study (21). In an Iranian sample including 117 patients with bipolar disorder type I and 200 control subjects, the authors found no significant difference between $T$. gondii seropositivity and bipolar disorder (22). Similarly, in other studies with smaller sample sizes conducted in Germany $(23,24)$ and Mexico (25), no significant relationship between $T$. gondii seroprevalence and bipolar disorder was reported. In a recent meta-analysis included 11 different studies investigating the association between $T$. gondii and bipolar disorder, Snijders et al. (31) revealed that the overall OR was not significant for T. gondii (OR=1.4, $\mathrm{p}>0.05)$. However, the authors indicated that $T$. gondii exposure may be a risk factor for bipolar disorder in certain age groups and subpopulations (31).

Prenatal exposure to neurotropic infectious agents is known to be a possible risk factor for later development of mental disorders. Several studies demonstrated that maternal infection with $T$. gondii was associated with a higher risk of schizophrenia in adult offspring $(15,16)$. However, in two different case-control studies performed by Mortensen et al. (32), and Freedman et al. (33), no statistically significant association was observed between prenatal exposure to $T$. gondii and the risk of bipolar disorder in adult offspring. The authors suggested that congenital T. gondii 
Table 2. Comparison of socio-demographic data and possible risk factors for $T$. gondii infection in seropositive/seronegative patients and in all seropositive/seronegative participants

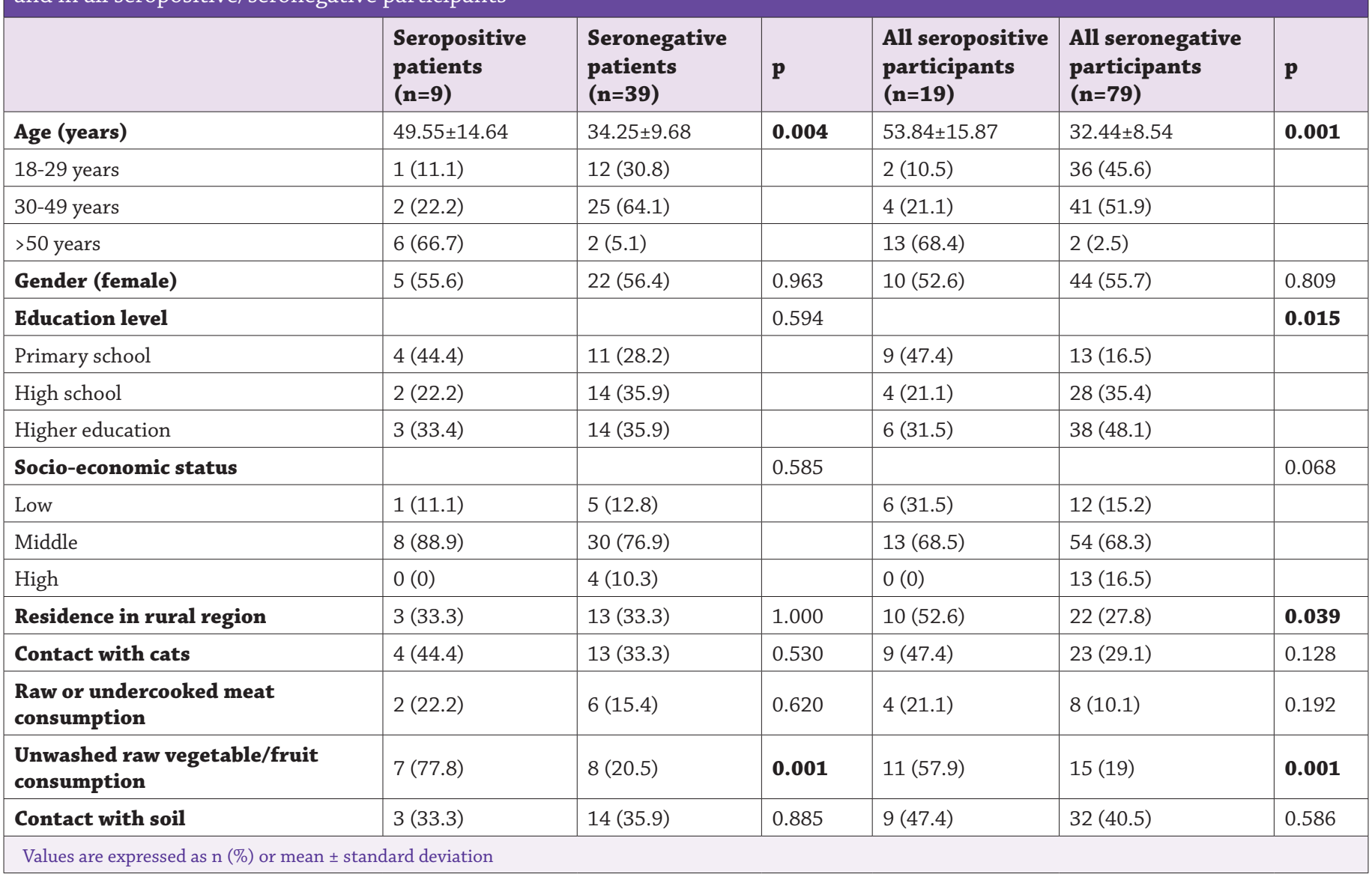

infection could be a risk factor only for the development of schizophrenia and related psychosis, but not for bipolar disorder.

Reasons for this contradictory results across the studies mentioned above are not known with certainty, but may include methodological differences in the serological diagnosis, differences in the prevalence of T. gondii infection, the timing of infection, or differences in the genetic background of the participants. On the other hand, our study has the similar limitations that were pointed out in previous seroprevalence studies. Failure to estimate the initiation of exposure is one of the most important difficulties in these studies, and in our research, we were not able to determine the duration of exposure to T. gondii infection in patients with bipolar disorder. Control subjects did not undergo a structured clinical interview like DSM-IV, the absence of personal or family history of psychiatric disorder in the control group was obtained from their statements (via non-structured clinical interview) and their medical records. Another limitation was that medications (mood stabilizers, antipsychotics, etc.) or other unpredictable confounding factors might affect the antibody levels in patient group. Furthermore, our results should be interpreted with caution because of relatively small sample size. Beside these limitations, the present study has a number of strengths. First, we minimized unwanted heterogeneity by studying participants with similar chronological age. Because of the fact that the prevalence of $T$. gondii infection increases with age, it is important to reduce the chance of fraudulent relationships obtaining from age-related exposure differences. Second, we used an automated and standardized laboratory method to determine the serum antibody levels.

\section{CONCLUSION}

In conclusion, our preliminary findings do not support the hypothesis that latent $T$. gondii infection is related to bipolar disorder. However, in the presence of conflicting reports, the potential role of toxoplasmosis in bipolar disorder cannot be completely ruled out. It is necessary to perform further studies with larger sample sizes to clarify the effect of latent toxoplasmosis on the development of bipolar disorder.

\section{* Ethics}

Ethics Committee Approval: Ethical approval was obtained from the Ethics Committee of Süleyman Demirel University Faculty of Medicine (decision no: 242, date: 13/12/2018).

Informed Consent: Written informed consent was taken from all the participants.

Peer-review: Internally peer-reviewed.

\section{* Authorship Contributions}

Surgical and Medical Practices: F.K., A.D., Concept: M.C.Ş., F.K., B.A., E.S.Ç., Design: M.C.Ş., F.K., B.A., E.S.Ç., Data Collection or Processing: M.C.Ş., F.K., A.D., B.A., E.S.Ç., Analysis or Interpretation: M.C.Ş., F.K., A.D., B.A., E.S.Ç., Literature Search: M.C.Ş., A.D., B.A., E.S.Ç., Writing: M.C.Ş., F.K.

Conflict of Interest: No conflict of interest was declared by the authors.

Financial Disclosure: The authors declared that this study received no financial support. 


\section{REFERENCES}

1. Merikangas KR, Jin R, He JP, Kessler RC, Lee S, Sampson NA, et al. Prevalence and correlates of bipolar spectrum disorder in the world mental health survey initiative. Arch Gen Psychiatry 2011; 68: 241-51.

2. Phillips ML, Kupfer DJ. Bipolar disorder diagnosis: challenges and future directions. Lancet 2013; 381: 1663-71.

3. Dean BB, Gerner D, Gerner RH. A systematic review evaluating healthrelated quality of life, work impairment, and healthcare costs and utilization in bipolar disorder. Curr Med Res Opin 2004; 20: 139-54.

4. de Barros JLVM, Barbosa IG, Salem H, Rocha NP, Kummer A, Okusaga $\mathrm{OO}$, et al. Is there any association between Toxoplasma gondii infection and bipolar disorder? A systematic review and meta-analysis. J Affect Disord 2017; 209: 59-65.

5. Del Grande C, Galli L, Schiavi E, Dell'Osso L, Bruschi F. Is Toxoplasma gondii a Trigger of Bipolar Disorder? Pathogens 2017; 6: 3 .

6. Fekadu A, Shibre T, Cleare AJ. Toxoplasmosis as a cause for behaviour disorders--overview of evidence and mechanisms. Folia Parasitol (Praha) 2010; 57: 105-13.

7. Hamdani N, Daban-Huard C, Lajnef M, Richard JR, Delavest M, Godin $\mathrm{O}$, et al. Relationship between Toxoplasma gondii infection and bipolar disorder in a French sample. J Affect Disord 2013; 148: 444-8.

8. Yüksel P, Kocazeybek B. Do Microorganisms Have a Role in Neuropsychiatric Diseases? FLORA 2013; 18: 59-65.

9. Yolken RH, Torrey EF. Are some cases of psychosis caused by microbial agents? A review of the evidence. Mol Psychiatry 2008; 13: 470-9.

10. Montoya JG, Liesenfeld O. Toxoplasmosis. Lancet 2004; 363: 1965-76.

11. Halonen SK, Weiss LM. Toxoplasmosis. Handb Clin Neurol 2013; 114: $125-45$.

12. Dubey JP. The history of Toxoplasma gondii--the first 100 years. J Eukaryot Microbiol 2008; 55: 467-75.

13. Flegr J. How and why Toxoplasma makes us crazy. Trends Parasitol 2013; 29: 156-63.

14. Pearce BD, Kruszon-Moran D, Jones JL. The relationship between Toxoplasma gondii infection and mood disorders in the third National Health and Nutrition Survey. Biol Psychiatry 2012; 72: 290-5.

15. Torrey EF, Bartko JJ, Lun ZR, Yolken RH. Antibodies to Toxoplasma gondii in patients with schizophrenia: a meta-analysis. Schizophr Bull 2007; 33: 729-36.

16. Sutterland AL, Fond G, Kuin A, Koeter MW, Lutter R, van Gool T, et al. Beyond the association. Toxoplasma gondii in schizophrenia, bipolar disorder, and addiction: systematic review and meta-analysis. Acta Psychiatr Scand 2015; 132: 161-79.

17. İnceboz M, Inceboz T. Toxoplasmosis and Neuropsychological Effects. Turkiye Parazitol Derg 2021; 45: 49-55.

18. Tedla Y, Shibre T, Ali O, Tadele G, Woldeamanuel Y, Asrat D, et al. Serum antibodies to Toxoplasma gondii and Herpesvidae family viruses in individuals with schizophrenia and bipolar disorder: a case-control study. Ethiop Med J 2011; 49: 211-20.
19. Chen X, Chen B, Hou X, Zheng C, Yang X, Ke J, et al. Association between Toxoplasma gondii infection and psychiatric disorders in Zhejiang, Southeastern China. Acta Trop 2019; 192: 82-6.

20. Del Grande C, Schiavi E, Masci I, Barbuti M, Maccariello G, Massimetti G, et al. Toxoplasmosis in a Cohort of Italian Patients With Bipolar and Psychotic Disorders: How Infection May Affect Clinical Features? J Nerv Ment Dis 2020; 208: 118-26.

21. Doğan N, Akdaş İ, Eşsizoğlu A, Güleç G. Serological and Molecular Investigation of the Presence and Association of Toxoplasma gondii in Bipolar Affective Disorder and Schizophrenic Patients. FLORA 2018; 23 : 142-9.

22. Khademvatan S, Khajeddin N, Izadi S, Saki J. Study of Toxoplasma gondii infection in patients with bipolar disorder. J Med Sci 2013; 13: 215-20.

23. Gerber SI, Krienke UJ, Biedermann NC, Grunze H, Yolken RH, Dittmann $S$, et al. Impaired functioning in euthymic patients with bipolar disorder-HSV-1 as a predictor. Prog Neuropsychopharmacol Biol Psychiatry 2012; 36: 110-6.

24. Stich O, Andres TA, Gross CM, Gerber SI, Rauer S, Langosch JM. An observational study of inflammation in the central nervous system in patients with bipolar disorder. Bipolar Disord 2015; 17: 291-302.

25. Alvarado-Esquivel C, Alanis-Quiñones OP, Arreola-Valenzuela MA, Rodríguez-Briones A, Piedra-Nevarez LJ, Duran-Morales E, et al. Seroepidemiology of Toxoplasma gondii infection in psychiatric inpatients in a northern Mexican city. BMC Infect Dis 2006; 6: 178.

26. Tanaka T, Matsuda T, Hayes LN, Yang S, Rodriguez K, Severance EG, et al. Infection and inflammation in schizophrenia and bipolar disorder. Neurosci Res 2017; 115: 59-63.

27. Hinze-Selch D, Däubener W, Erdag S, Wilms S. The diagnosis of a personality disorder increases the likelihood for seropositivity to Toxoplasma gondii in psychiatric patients. Folia Parasitol (Praha) 2010; 57: 129-35.

28. Flegr J, Prandota J, Sovičková M, Israili ZH. Toxoplasmosis--a global threat. Correlation of latent toxoplasmosis with specific disease burden in a set of 88 countries. PLoS One 2014; 9: e90203.

29. Kolören Z, Dubey JP. A review of toxoplasmosis in humans and animals in Turkey. Parasitology 2020; 147: 12-28.

30. Malatyalı E, Yıldız İ, Tileklioğlu E, Ertabaklar H, Ertuğ S. Retrospective Analysis of Toxoplasma gondii Serology Results from Adnan Menderes University Faculty of Medicine Parasitology Laboratory from 2007 to 2017. Turkiye Parazitol Derg 2019; 43: 1-4.

31. Snijders GJLJ, van Mierlo HC, Boks MP, Begemann MJH, Sutterland $\mathrm{AL}$, Litjens $\mathrm{M}$, et al. The association between antibodies to neurotropic pathogens and bipolar disorder : A study in the Dutch Bipolar (DB) Cohort and meta-analysis. Transl Psychiatry 2019; 9: 311.

32. Mortensen PB, Pedersen CB, McGrath JJ, Hougaard DM, NørgaardPetersen B, Mors O, et al. Neonatal antibodies to infectious agents and risk of bipolar disorder: a population-based case-control study. Bipolar Disord 2011; 13: 624-9.

33. Freedman D, Bao Y, Shen L, Schaefer CA, Brown AS. Maternal T. gondii, offspring bipolar disorder and neurocognition. Psychiatry Res 2016; 243: 382-9. 